\title{
A REVIEW OF STRATEGIES FOR THE EXCLUSION OF DEEP VEIN THROMBOSIS AND PULMONARY EMBOLISM
}

\author{
A Macheta, Consultant Haematologist, \\ Furness General Hospital
}

It is becoming increasingly common practice across the UK to investigate and manage suspected cases of deep vein thrombosis (DVT) and, to a lesser extent, pulmonary embolism (PE) on an outpatient basis. A major advance enabling this has been the introduction to clinical use of the low molecular weight heparins. These can be given as oncedaily subcutaneous injections and appear to be of comparable efficacy to standard intravenous heparin. With the exceptions of renal failure (and, possibly, pregnancy) low molecular weight heparin therapy does not require routine coagulation monitoring although it is good and accepted practice to monitor the platelet count in view of the small risks of heparin-induced thrombocytopenia. Conventional practice has been to admit the patient under heparin cover until the result of radiological investigation, usually a venogram, is known. Ultrasonography is widely used and good at diagnosing proximal DVT but is less precise in detecting distal DVT. Although the latter are much less likely to result in PE, around $20 \%$ will extend proximally over a period of around a week with significant risks of embolism ${ }^{(1)}$. Thus, reliance on a single ultrasound scan by itself cannot be used safely to exclude a DVT and although serial ultrasonography has been used this would pose a large burden on already over-stretched radiological services. Contrast venography remains the gold standard for the diagnosis and exclusion of DVT. This remains an invasive, often painful procedure, technically unsuccessful in around $10 \%$ of cases. The diagnosis of DVT purely on the basis of clinical symptoms and signs is notoriously unreliable ${ }^{(2)}$. Thus it would be very useful if simple non-invasive tests could be introduced to predict with reasonable certainty those patients unlikely to have a DVT or PE, saving them from having further invasive tests of coming into hospital.

Over the past 10 years or so several laboratory tests for measuring markers of in-vivo thrombosis have been developed (Table 1). These appear to be very sensitive but have limited specificity for intra-vascular thrombosis. Raised levels may be encountered with haematomas, tissue damage following transfusion and in pregnancy. As discussed below, these can have high negative predictive values for excluding DVT or PE although it should be appreciated that there are no sharp cut-off values that readily distinguish positive and negative results. Also, levels will vary depending on which particular assay is used. In view of this, cut-off values need to be established as part of clinical management protocols rather

- Thrombin - Anti-thrombin III complexes

- Fibrino-peptide A

- Prothrombin fragments 1 and 2

- Fragment E

- D-Dimer than using quoted or accepted levels derived from normal individuals. Of the many putative markers only D-dimer has become widely used so far. D-dimer is a fragment released from cross-linked fibrin as it undergoes fibrinolysis. Several methods have been developed that are suitable for on-call or emergency use and are discussed below. The three laboratories across Morecambe Bay are now capable of measuring $\mathrm{D}$-dimer and this is now being introduced in combination with clinical probability scores in the exclusion of DVT and PE.

This review describes some of the diagnostic strategies used to exclude DVT/PE and provides a background for some of the audit work undertaken on this subject in Lancaster and Barrow over the past year that is presented in this journal (Tina Kozlowski, pages 416-418).

\section{GOLD STANDARDS}

Most authorities still consider contrast venography to be the gold standard for the diagnosis and exclusion of DVT. Pulmonary angiography is currently the standard as regards PE although most hospitals do not have this facility and rely on the less sensitive ventilation/perfusion isotopic lung scan. Contrast venography has shown that only $20-40 \%$ of patients with a clinical diagnosis of DVT actually have the condition $^{(2)}$. This begs the question as to the fate of those patients on whom a negative results leads to no subsequent anticoagulant therapy. Hull et al followed up 160 patients who had undergone negative venograms over a period of three months with no therapy ${ }^{(3)}$. Three venous thromboembolic events were observed during this time, giving a venous thromboembolic complication rate of $1.9 \%$. Novelline et al performed pulmonary angiography in all clinically suspected $\mathrm{PE}^{(4)}$. Anticoagulants were not given if this proved negative and over a six-month follow-up there were three confirmed venous thromboembolic events in 167 patients, giving a rate of $1.8 \%$. These figures should be used to compare the rates in other management strategies. During a short follow-up after a normal isotope lung scan, confirmed DVT or PE occurs in around $0.5 \%$ of cases $^{(5,6)}$.

\section{ULTRASONOGRAPHY}

Ultrasonography, using compression techniques, duplex scanning and colour flow is good at diagnosing proximal DVT with sensitivities of $95-97 \%$ and specificities of $93-98 \%$ (Table 2) ${ }^{(7)}$. It is less reliable in diagnosing distal or calf DVT (sensitivity of $40-90 \%$ ) (Table 3$)^{(7)}$. Isolated calf DVT has a very low risk of embolism but may be associated with late complications such as chronic venous insufficiency and postthrombotic syndromes. Proximal extension may nevertheless 


\begin{tabular}{|l|c|c|}
\hline & $\begin{array}{c}\text { Sensitivity } \\
\mathbf{9 5 \%} \mathbf{~ C l}\end{array}$ & $\begin{array}{c}\text { Specificity } \\
\mathbf{9 5 \%} \mathbf{~ C l}\end{array}$ \\
\hline Compression & $95 \%$ & $98 \%$ \\
ultansonography & $93-97 \%$ & $96-99 \%$ \\
\hline Duplex ultrasonography & $95 \%$ & $93 \%$ \\
& $89-98 \%$ & $87-97 \%$ \\
\hline Colour coded doppler & $97 \%$ & $97 \%$ \\
& $92-99 \%$ & $90-97 \%$ \\
\hline Impedance & $88 \%$ & $95 \%$ \\
plethysmography & $86-90 \%$ & $94-96 \%$ \\
\hline
\end{tabular}

Table 2 Accuracy of diagnostic methods for diagnosis of proximal DVT

\begin{tabular}{|l|c|}
\hline & Sensitivity \\
\hline Compression ultansonography & $\sim 87 \%$ \\
\hline Duplex ultrasonography & $\sim 40 \%$ \\
\hline Colour coded doppler & $\sim 75 \%$ \\
\hline
\end{tabular}

Table 3 Accuracy of ultrasound in isolated symptomatic calf vein thrombosis

occur during the first week and if a decision is made to withhold anticoagulation on the basis of an absence of proximal clot then serial ultrasonography needs to be performed. Several studies involving large numbers of patients scanned several times for up to eight days have assessed the efficacy of negative serial compression ultrasonography as a basis to withhold anticoagulant therapy ${ }^{(9,10,11,12)}$. Thrombo-embolic events have been assessed using venography or pulmonary angiography. The percentages of DVT and PE seen up to three months followup has varied from 0.6 to $1.5 \%$ with pooled results yielding a figure of around $0.8 \%$ (Table 4 ).

\begin{tabular}{|l|c|}
\hline \multicolumn{2}{|c|}{ Normal compression ultrasound over days 1-8 } \\
\hline Study & $\begin{array}{c}\text { Percentage symptomatic } \\
\text { DVT or PE over 3 months }\end{array}$ \\
\hline Sluzewski et al (1991) & $1.3 \%$ \\
\hline Heijboer et al (1993) & $1.5 \%$ \\
\hline Cogo et al (1998) & $0.7 \%$ \\
\hline Birdwell et al (1998) & $0.6 \%$ \\
\hline Pooled** & $0.8 \%$ \\
\hline \multicolumn{2}{|c|}{${ }^{* *}$ pooled events 13 DVT 4 PE } \\
\hline
\end{tabular}

Table 4 Serial compression ultrasonography for diagnosing DVT

\section{IMPEDANCE PLETHYSMOGRAPHY (IPG)}

This non-invasive bedside test has been available for many years and is seen as an alternative to ultrasound scanning. It is popular in parts of Europe but little used in the UK. Lately, the equipment has become easier to use, is standardised (with computer-aided diagnosis) and can be used by staff after a short period of training. Although pretty sensitive for the diagnosis of proximal DVT (sensitivity of $86-90 \%)^{(7)}$, it is much less reliable and hence clinically useless for distal DVT. Partial non-occlusive proximal clots may be missed and it cannot distinguish between clot and extrinisic venous constriction. Nevertheless, as the technique has become more user-friendly, it has been adopted in some hospitals as part of their management strategy. Serial readings need to be taken over a period of seven to eight days in view of the possibility of proximal extension. Several studies have assessed the usefulness of serial IPG as a basis for withholding anticoagulant therapy over periods of six to twelve months in those patients with repeatedly negative results. Confirmed venous thrombo-embolic events over this period assessed using the gold standard methods are around 0.8 to $2.6 \%$ Pooling the results of these studies gives a figure of around $1.8 \%$ with $0.7 \%$ confidence intervals (Table 5$)^{(10,13,14,15,16)}$. There were 18 confirmed DVTs three PEs and one death from PE when 1,395 patients were followed prospectively following negative serial IPGs.

\begin{tabular}{|c|c|c|c|}
\hline \multicolumn{2}{|c|}{ Normal IPGs over $1-2$ weeks } & \multicolumn{2}{|c|}{ 6-12 months follow-up } \\
\hline \multirow{2}{*}{$\begin{array}{l}\text { Study } \\
\text { Hull et al (1985) }\end{array}$} & \multicolumn{3}{|c|}{$\begin{array}{l}\text { Percentage symptomatic venous } \\
\text { thromboembolic events confirmec }\end{array}$} \\
\hline & & $1.7 \%$ & $3.1 \% *$ \\
\hline Huisman et al (1986) & & $0.7 \%$ & $1.6 \%^{*}$ \\
\hline Huisman et al (1989) & & $0.8 \%$ & $2.2 \%^{\star}$ \\
\hline Prandoni et al (1991) & & $2.6 \%$ & $4.3 \%{ }^{\star}$ \\
\hline Heijboer et al (1993) & & $2.4 \%$ & $4.0 \%^{*}$ \\
\hline Pooled & & $1.8 \%$ & $2.5 \% *$ \\
\hline \multicolumn{4}{|c|}{${ }^{\star}=$ upper $95 \%$ confidence intervals } \\
\hline
\end{tabular}

Table 5 Serial impedance plethysmography

\section{PRE-TEST PROBABILITY SCORES FOR DVT AND PE}

Patients are given a score depending on several simple clinical parameters that describe the likelihood of DVT. The scoring system most widely used is described by Wells ${ }^{(17)}$ and is summarised in Table 6. On this basis patients are divided into three groups, i.e. high, moderate and low probability of DVT. When these subgroups are assessed using contrast venography the incidence of DVT is around $85 \%$ for the high group, $33 \%$ for the moderate group and only $5 \%$ for the low group. The score is not robust enough to be used by itself when considering anticoagulation therapy but can be combined usefully with the results of other investigations such as D-dimer. Recently, Wells $(2000)^{(18)}$ described a clinical probability score that can be used in conjunction with D-dimer in excluding PE without the need for scanning.

\begin{tabular}{lc} 
- Active cancer & Points \\
- Paralysis, paresis or recent plaster & 1 \\
- Recently bed-ridden and/or recent surgery & 1 \\
- Localized tenderness along veins & 1 \\
- Entire leg swollen & 1 \\
- Calf swelling > $3 \mathrm{~cm}$ than asymptomatic side & 1 \\
- Pitting oedema & 1 \\
- Collateral superficial veins (non-varicose) & 1 \\
Alternative diagnosis & 1 \\
Probability groups - High & $\geq 3$ \\
$\quad$ - Moderate & $1-2$ \\
$\quad \leq 0$ & \\
\hline
\end{tabular}

Table 6 Pre-test probability score for DVT from Wells et al. (1995)

\section{D-DIMER TESTS IN THE DIAGNOSIS OF DVT AND PE}

Several methods have been used to measure D-dimer, most having very good sensitivity but show a much lower specificity for venous thrombo-embolic events. The gold standard test is the ELISA, having a sensitivity of around $97 \%$ for DVT and $98.8 \%$ for PE, with $27-54 \%$ specificities. 
The ELISA-based methods are generally unsuitable for emergency or on-call use but several methods have been established that can be used quickly on-call and even at the bedside. They are now commercially available, the most popular being Nycomed and Vidas, which are membranebased rapid ELISA tests and SimpliRed, which is based on red cell agglutination using bi-specific monoclonal antibody directed against D-dimer and red cells. Results are available within a few minutes. In assessing the usefulness of these tests, their negative predictive values should be considered, i.e. how often they predict even small thrombo-embolic events that would be picked up by the gold standard techniques of contrast venography or pulmonary angiography. Negative predictive values of around 83-99\% for DVT and $88-99 \%$ for PE are obtainable with these tests (Tables 7 and 8$)^{(8)}$. The D-dimer levels obtained using these tests are not equivalent and in particular the cut-off values will differ. The clinical usefulness of a particular method and the cut-off levels need to be validated as part of prospective clinical management trials.

\begin{tabular}{|l|c|c|c|c|}
\hline Method & $\begin{array}{c}\text { Sensitivity } \\
\%\end{array}$ & $\begin{array}{c}\text { Specificity } \\
\%\end{array}$ & $\begin{array}{c}\text { Positing } \\
\text { predictive } \\
\text { value } \%\end{array}$ & $\begin{array}{c}\text { Negative } \\
\text { predictive } \\
\text { value } \%\end{array}$ \\
\hline Elisa & $97 \%$ & $54.3 \%$ & $58 \%$ & $97 \%$ \\
\hline Rapid Elisa & $94.3 \%$ & $72 \%$ & $65.7 \%$ & $98 \%$ \\
\hline Latex agglutn. & $77.3 \%$ & $79.2 \%$ & $74.3 \%$ & $83.3 \%$ \\
\hline SimpliRed & $89 \%$ & $77 \%$ & $74.3 \%$ & $95 \%$ \\
\hline
\end{tabular}

Table 7 Evaluation of D-dimer assays using venography as reference standard in all patients with clinically suspected DVT

\begin{tabular}{|l|c|c|c|c|}
\hline Method & Sensitivity & Specificity & $\begin{array}{c}\text { Positing } \\
\text { predictive } \\
\text { value }\end{array}$ & $\begin{array}{c}\text { Negative } \\
\text { predictive } \\
\text { value }\end{array}$ \\
\hline Elisa & $98.8 \%$ & $27.7 \%$ & $42.8 \%$ & $98.6 \%$ \\
\hline Rapid Elisa & $98.5 \%$ & $41.0 \%$ & $38.5 \%$ & $98.5 \%$ \\
\hline Latex & 91.7 & $33.0 \%$ & $42.7 \%$ & $88.3 \%$ \\
\hline SimpliRed & $89.0 \%$ & $67.0 \% \%$ & $36.5 \%$ & $97.0 \%$ \\
\hline
\end{tabular}

Table 8 D-dimer assays in the diagnosis of pumlonary embolus

The D-dimer method used in the three hospitals across Morecambe Bay is based on an immuno-turbidometric assay using latex particles coated with antibodies against D-dimer (IL Test D-dimer). It is quick, has the advantage of being automated and can be used on the routine laboratory coagulometers. It has been less extensively studied than other D-dimer methods for the exclusion of DVT/PE but recent work suggests comparable negative predictive values. The cutoff value has been quoted as $280 \mu \mathrm{g} / \mathrm{l}$. Currently the use of the IL Test D-dimer in isolation for the exclusion of DVT or PE is not recommended until further experience has been gained.

\section{COMBINED STRATEGIES FOR THE DIAGNOSIS OF DVT}

Some recent studies have looked at the use of compression ultrasonography combined with either a D-dimer or the result of a clinical probability score. The scan should establish whether a proximal DVT is present or not, the hope being that the D-dimer would pick up the smaller calf clots. As with other studies, patients with negative findings are not anticoagulated, followed up and the subsequent thromboembolic event rates in this population are established. The combination of ultrasonography and Ddimer gave rates of 0.4 to $0.6 \%$ with upper $95 \%$ confidence limits of $0.9-1.7 \%$. Ultrasonography and the Well's clinical probability score gave a figure of $0.6 \%$ with an upper confidence level of 1.3 (Table 9) $^{(19,20,21)}$.

\begin{tabular}{|l|cc|}
\hline Study & $\begin{array}{c}\text { Percentage symptomatic } \\
\text { venous thromboembolic } \\
\text { events }\end{array}$ \\
\hline Ultrasound and D-dimer & $0.9 \%$ & $\left(1.7 \%^{*}\right)$ \\
Kaaijenhagen et al (1997) & $0.4 \%$ & $\left(0.9 \%^{*}\right)$ \\
Bernardi et al (1998) & $0.6 \%$ & $\left(1.0 \%^{*}\right)$ \\
Pooled results: & $0.6 \%$ \\
\hline Ultrasound and Clinical Score & $\left(1.3 \%{ }^{*}\right)$ \\
Wells et al (1997) & \multicolumn{2}{|c|}{ *Upper 95\% confidence interval } \\
\hline \multicolumn{2}{|c|}{} \\
\hline
\end{tabular}

Table 9 Compression ultrasound with other tests

\section{CAN DVT AND PE BE EXCLUDED WITHOUT RESORT TO RADIOLOGICAL INVESTIGATIONS?}

Many hospitals in the UK are now using D-dimer in association with a clinical probability score or other simple screening tests such as light reflex rheography to exclude DVT as part of outpatient management strategies to exclude DVT and further radiological investigations (Table 6). Typically, patients with a negative D-dimer result and a moderate or low Wells probability score are discharged on no treatment. Either a high score or a positive D-dimer results in anticoagulation with low molecular weight heparin pending the result of diagnostic radiology. At the recent XVIIIth Congress of the International Society on Thrombosis and Haemostasis in Paris this year, there were many papers reporting the usefulness of D-dimer in the exclusion of DVT and PE, emphasising its high negative predictive value and how it has made a major impact on the number of diagnostic radiological investigations undertaken. Although some speakers reported that a negative D-dimer could be used by itself to exclude DVT and PE, significant doubt remains. In what appears to be the largest randomised and prospective diagnostic management study so far undertaken, involving over 800 patients followed up for at least three months, the combination of a clinical probability score and D-dimer testing to exclude DVT appeared to be as safe and effective as serial ultrasonography ${ }^{(22)}$. It was reassuring to see that the IL D-dimer test, which is to be adopted by the laboratories in Morecambe Bay, was used in this study. The Manchester group also reported a high negative predictive value for this test $(\mathrm{NPV}=97 \%)$ and interestingly found that the SimpliRed test, which was used by their casualty staff, performed rather poorly $(\mathrm{NPV}=82 \%)^{(23)}$

It now appears that by using D-dimer and a clinical probability score for PE many patients can now be spared further investigation. Wells et $a l^{(18)}$ described a clinical score (summarised in Table 10) on the basis of which patients are stratified into three groups of low, moderate or high probability for PE. A negative D-dimer test (SimpliRed was used) and a clinical probability score of less than 4 gives a negative predictive value of around $99 \%$, so obviating the need for further tests such as isotope lung scanning. A similar high NPV of $97.4 \%$ using the same scoring system but using the IL test D-dimer was reported at the Paris Congress from the Southampton University Hospital ${ }^{(24)}$. 


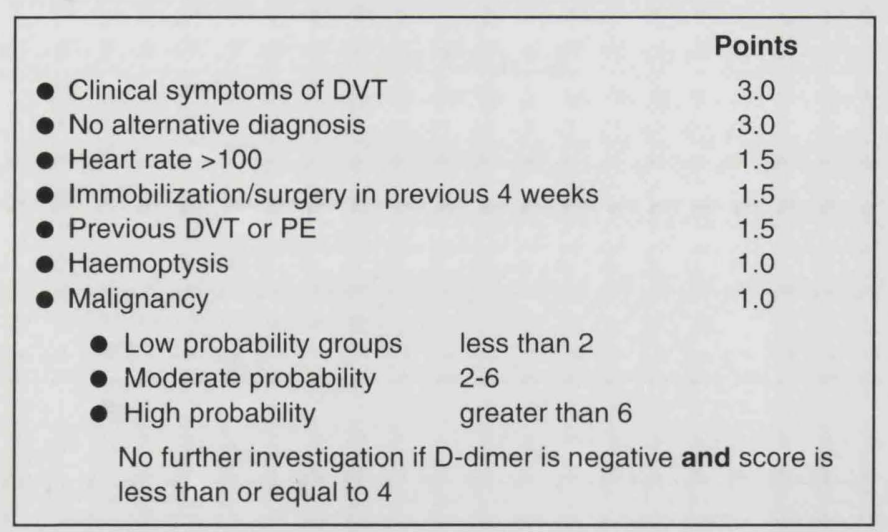

Table 10 Probability Score for PE - From Wells et al (2000)

\section{SUMMARY}

D-dimer has now become firmly established as an important test in the management of patients suspected of having DVT or PE. Its widespread use in diagnostic management strategies over the past two or three years is now being backed up by the results of recent prospective studies concluding that it can be used safely to identify patients who do not have a DVT or PE. It is, however, too premature to rely on the D-dimer test alone and it should be used only in conjunction with another screening test such as the clinical probability scores described by Wells. Further studies may possibly be needed to define or revise cutoff levels. The recently introduced IL test D-dimer seems to perform as well as or better than the other D-dimer tests.

\section{REFERENCES}

1 Lagerstadt CI, Olsson CG, Fagher BO et al. Need for longterm treatment in symptomatic calf-vein thrombosis. Lancet 2(8454): 515-518, 1985

2 Prandoni P, Mannucci PM. Deep vein thrombosis of the lower limbs: diagnosis and management. Clin Haematol (Baillieres) 12:3 p533-554, 1999.

3. Hull R, Hirsh J, Sackett DA et al. Clinical validity of a negative venograrn in patients with clinically suspected venous thrombosis. Circulation 64:622-625, 1981

4 Novelline RA, Baltarowich $\mathrm{OH}$, Athanasoulis CA, et al. The clinical course of patients with suspected pulmonary embolism and a negative pulmonary arteriogram. Radiology 126:561-567, 1978

5 van Beek EJ, Kuyer PM, Schenk BE et al. A normal perfusion lung scan in patients with clinically suspected pulmonary embolism. Frequency and clinical validity. Chest 108:170-173, 1995

6 Hull RD, Raskob GE, Coates Geand Panju AA. Clinical validity of a normal perfusion lung scan in patients with suspected pulmonary embolism. Chest 97:23-26, 1990.

7. Kraaijenhagen RA, Lensing AWA, Wallis JW et al. Diagnostic management of venous thrombo-embolism. Clin Haematol (Baillieres). 11:3:1998 p 541-586.

8 Lee AY, Ginsberg JS. Laboratory diagnosis of venous thrombo-embolism. Clin Haematol (Baillieres) 11:3: $1998 \mathrm{p}$ 587-604.

9 Sluzewski M, Koopman MM, Schuur KH et al. Influence of negative ultrasound findings on the management of in- and outpatients with suspected deep-vein thrombosis. Eur J Radiol 13:174-177, 1991

10 Heijboer H, Buller HR, Lensing AW et al. A comparison of real-time compression ultrasonography with impedance plethysmography for the diagnosis of deep vein thrombosis in symptomatic outpatients. New Eng J Med 329:1365-1369, 1993 11. Cogo A, Lensing AW, Koopman MM et al. Simplified compression ultrasound strategy for the diagnostic management of patients with clinically suspected venous thrombosis. Br Med J 316:17-20, 1998

12 Birdwell B, Raskob G, Whitsett T et al. Clinical validity of normal compression ultrasonography in outpatients suspected of having deep venous thrombosis. Ann Int Med 128:1-7, 1998 13 Hull RD, Hirsh J, Carter CJ et al. Diagnostic efficacy of impedance plethysmography for clinically suspected deep-vein thrombosis. A randomized trial. Ann Int Med 1022:21-28, 1985 14 Huisman MV, Buller HR, tenCate JW and Vreeken J. Serial impedance plethysmography for suspected deep venous thrombosis in outpatients. The Amsterdam General Practitioner Study. New Eng J Med 314:823-828, 1986

15 Huisman MV, Buller HR ten, Cate JW, et al. Management of clinically suspected acute venous thrombosis in outpatients with serial impedance plethysmography in a community hospital setting. Arch Int Med 149:511-513, 1989

16 Prandoni P, Lensing AW, Huisman MV et al. A new computerized impedance plethysmograph: accuracy in the detection of proximal deep vein thrombosis in symptomatic outpatients. Thrombosis and Haemostasis 65:229-232, 1991

17 Wells PS, Anderson, DR et al. Accuracy of clinical assessment of deep-vein thrombosis. Lancet 345:1326-1330, 1995

18 Wells PS, Anderson DR, Rodgers M et al. Derivation of a simple clinical model to categorize patients probability of pulmonary embolism: increasing the model utility with the SimpliRed D-dimer. Thrombosis and Haemostasis 83:416-420, 2000

19 Kraaijenhagen RA, Koopman MM, Bernardi E et al. Simplification of the diagnostic management of outpatients with symptomatic deep vein thrombosis with D-Dimer measurements. Thrombosis and Haemostasis, supplement 159:PD 652 (abstract), 1997

20 Bernardi E, Prandoni P, Lensing AWA et al. D-dimer testing as an adjunct to ultrasonography in patients with clinically suspected deep vein thrombosis: prospective cohort study. $\mathrm{Br}$ Med J 317:1037-1040, 1998

21 Wells PS, Anderson DR, Borrnanis J et al. Management of patients with suspected deep vein thrombosis based on clinical probability. Lancet 350:1795-1798, 1997

22 Wells PS, Rodger M, Forgie M et al. A randomised trial in patients with suspected DVT comparing a D-dimer/Clinical probability strategy to clinical probability, prior to ultrasoundimaging. D-Dirner safely reduces the need for diagnosting imaging. Thrombosis and Haemostasis, supplement, Abstract number: OC41, July 2001 XVIII Congress of the International Society on Thrombosis and Haemostasis, July 6-12, 2001, Paris, France

23. Jones S, Lane B, Macway-Jones K. Cumming T. Ruling out deep vein thrombosis in the emergency department: a prospective diagnostic management study that compares SimpliRed and IL-Test D-dimer assays. Thrombosis and Haemostasis, supplement, Abstract number: P719, July 2001 XVIII Congress of the International Society on Thrombosis and Haemostasis, July 6-12, 2001, Paris, France

24 El-Batarny HS, Othman MA, O'Shaughnessy DF. A combination of a simple clinical model and advanced latex Ddimer assay can be safely used for exclusion of pulmonary embolism. Thrombosis and Haemostasis, supplement, Abstract number P7-38, July 2001 XVIII Congess of the International Society on Thrombosis and Haemostasis, July 6-12, 2001, Paris, France 